Re-Submitted to: $\quad$ Process Biochemistry

Date: $\quad$ August 6, 2013

\title{
An innovative membrane bioreactor (MBR) system for simultaneous nitrogen and phosphorus removal
}

\author{
Fei-yun Sun ${ }^{\mathrm{a}, \mathrm{c}}$, Xiao-mao Wang ${ }^{\mathrm{b}, \mathrm{c}}$ and Xiao-yan $\mathrm{Li}^{\mathrm{c}}$ * \\ ${ }^{a}$ Harbin Institute of Technology Shenzhen Graduate School, Shenzhen 518055, China \\ b School of Environment, Tsinghua University, Beijing 100084, China \\ c Environmental Engineering Research Centre, Department of Civil Engineering, \\ The University of Hong Kong, Pokfulam Road, Hong Kong
}

(*Corresponding author: phone: 852-28592659; fax: 852-28595337; e-mail: xlia@hkucc.hku.hk)

1

2

\begin{abstract}
Membrane filtration was integrated with a post-denitrification process to form an innovative membrane bioreactor (MBR) system for effective organic degradation and nutrient ( $\mathrm{N}$ and $\mathrm{P}$ ) removal. The system comprised of an aerobic tank, an anoxic tank, an intermediate sedimentation tank, and a membrane filtration tank. The sedimentation tank functioned not only as a rough settler for sludge-water separation before membrane filtration, but also as an anaerobic chamber for P release. While half of the influent flowed into the aerobic tank, the other half was fed into the anoxic tank to favor the proliferation of phosphorus accumulating organisms (PAOs). The experiment was conducted continuously for about 430 days. With a short overall treatment time of less than 10 hrs for municipal wastewater, the MBR-based
\end{abstract}


11 process could achieve the total organic carbon, total nitrogen, and total phosphorus removals of around 94\%, 85\%, and 87\%, respectively. The growth and activity of PAOs in the MBR system were evidenced by the significant $\mathrm{P}$ release in the anaerobic chamber followed by the luxury $\mathrm{P}$ uptake in the membrane tank. With the DAPI and $\mathrm{PAO}_{\text {mix }}$ probe staining, the increases of PAOs and polyhydroxybutyrate (PHB) in sludge during the experiment were well observed under the fluorescent microscope.

Keywords: Biological nutrient removal; Enhanced biological phosphorus removal (EBPR); Fluorescence in situ hybridization (FISH); Membrane bioreactor (MBR); Wastewater treatment.

\section{Introduction}

Eutrophication has been recognized as one of the most serious water pollution problems. Wastewater discharge brings nutrients, both nitrogen $(\mathrm{N})$ and phosphorus $(\mathrm{P})$, into the receiving water, causing nutrient enrichment and algal blooms. For effective water environment protection, a number of nutrient removal processes have been developed for $\mathrm{N}$ and/or P removal from wastewaters [1]. Biological nitrogen removal involves the combined nitrification by autotrophic bacteria under aerobic conditions and denitrification by heterotrophic bacteria under anoxic conditions, while enhanced biological phosphorus removal (EBPR) is achieved through P luxury uptake by phosphorus accumulating organisms (PAOs) together with sludge discharge [2]. Biological $\mathrm{N}$ removal can be achieved by either pre-denitrification or post-denitrification [3]. Compared to the pre-denitrification process, post-denitrification would allow complete $\mathrm{N}$ removal [3], although the external carbon source usually needs to be added into the anoxic reactor. More recently, it was reported that simultaneous $\mathrm{N}$ and $\mathrm{P}$ removal could be achieved by placing an anaerobic tank before the 
aerobic tank (i.e. post-anoxic type), for which external carbon sources might not be required [4]. Although P removal was primarily driven by stored polyhydroxybutyrate (PHB) and other organic substances, it was apparent that a portion of PAOs was able to utilize nitrate as the electron acceptor [4].

Membrane bioreactor (MBR) is an attractive process that has been increasingly used for biological wastewater treatment. With membrane filtration replacing the conventional clarifier, MBR possesses a number of merits such as biomass enrichment, small footprint, ensured sludge-effluent separation, easy manipulation of the hydraulic and sludge retention times (HRT and SRT) and, most importantly, excellent effluent quality with little organic and solid contents [5, 6]. However, an MBR tank without anaerobic and anoxic variations cannot be simply used for nutrient removal in wastewater treatment. There is a need to develop innovative MBR systems that incorporate membrane separation into the biological treatment process for $\mathrm{N}$ and $\mathrm{P}$ removals.

In comparison to organic degradation, biological nutrient removal is more difficult to achieve with the MBR, and $\mathrm{P}$ is the most difficult one to remove $[1,7,8]$. Incorporation of membrane filtration into various processes for simultaneous $\mathrm{N}$ and $\mathrm{P}$ removal has been attempted in the past decade $[7,8]$. The system variations reported include sequencing batch reactors $[10,11]$, the continually-operated pre-oxic system $[8,9,12,13]$, and post-oxic denitrification type [4, 14]. For large-scale applications, the MBR has been used conventionally to replace the final clarifiers for solids-effluent separation in common nutrient removal activated sludge processes (e.g., the anaerobic-anoxic-oxic (A/A/O) process) (Table 1). These large-scale MBR systems often adopt a long treatment time or a low filtration rate for wastewater treatment and nutrient removal. Besides, although nutrient removal can be achieved in these systems, it has been found that denitrification sometimes may complicate 
the EBPR as denitrifiers compete with PAOs for the limited carbon source and hence affect the stability of the system performance [14].

Similar to any membrane separation process, membrane fouling in MBR is inevitable. A number of studies has suggested that the membrane fouling rate in MBR correlates well with the sludge concentration $[5,6]$. Thus, lowering the sludge concentration in the membrane chamber would help mitigate the fouling problem to some extent. However, the settleability of sludge has not been fully utilized for regulating the sludge concentration before membrane filtration in the MBR-based nutrient removal systems $[10,18]$. Moreover, when membrane is used to retrofit or upgrade existing biological wastewater treatment systems, some of the secondary clarifiers would often become obsolete.

In the present study, we developed a new system to integrate membrane filtration with the post-denitrification process for simultaneous $\mathrm{N}$ and $\mathrm{P}$ removal. The membrane chamber was connected to an intermediate sludge settler. As such, the sedimentation tank not only was used as a rough settler for sludge-water separation before membrane filtration but also provided an anaerobic zone to allow the proliferation and function of PAOs for P removal purpose. In addition to the development of an innovative and effective MBR wastewater treatment system for simultaneous $\mathrm{N}$ and $\mathrm{P}$ removal, PAO abundance and the $\mathrm{P}$ concentration profile throughout the system were characterized, and the long-term performance of the system was evaluated.

\section{Materials and Methods}

\subsection{Experimental set-up}

An MBR wastewater treatment system (Fig. 1) was developed and operated for the experimental study on the simultaneous removals of organic pollutants, nitrogen, and phosphorous. The system was a modification of the post-denitrification process that 
comprised of an aerobic tank, an anoxic tank, an intermediate sludge settler, and a membrane filtration tank. In addition to biomass concentration, the rough sludge settler also provided an anaerobic zone for P release. In the MBR tank, a polyethylene hollow-fiber membrane module ( $0.4 \mu \mathrm{m}$ pore size, $0.075 \mathrm{~m}^{2}$ effective area, Mitsubishi Rayon) was immersed. The working volumes of the aerobic, anoxic, settling, and membrane tanks were 2, 1.4, 1.5, and 1.6 L, respectively. Aeration was provided through fine air diffusers from the bottom in the aerobic tank and the membrane filtration tank, while sludge in the anoxic tank was suspended by a paddle mixer at $30 \mathrm{rpm}$. Half of the feed wastewater was pumped into the aerobic tank and the other half into the anoxic tank. The sludge recirculation ratios from the settling tank to the aerobic tank and from the membrane tank to the anoxic tank ranged from 300 to $400 \%$ (Table 2).

The feed consisted of $90 \%$ synthetic wastewater prepared according to a classic recipe [19] for typical municipal wastewater and $10 \%$ actual domestic sewage collected from a local municipal wastewater treatment plant (Stanley Sewage Treatment Plant, Hong Kong). The raw sewage was expected to supply trace elements for the biomass growth. The carbon source in the synthetic wastewater was a mixture of $90 \% \mathrm{NaAc}$ and $10 \%$ glucose, and the $\mathrm{N}$ and $\mathrm{P}$ sources in the feed were supplied with $\mathrm{NH}_{4} \mathrm{Cl}$ and a mixture of $\mathrm{KH}_{2} \mathrm{PO}_{4}$ and $\mathrm{NaH}_{2} \mathrm{PO}_{4}$, respectively. The variations of the wastewater influent in chemical oxygen demand (COD) and COD:N:P ratio are summarized in Table 2. $\mathrm{NaHCO}_{3}$ was added to the feed at $50 \mathrm{mg} / \mathrm{L}$ or higher to keep the $\mathrm{pH}$ between 6.5 and 7.5. Effluent was withdrawn through the membrane by a suction pump (MasterFLEX, Cole-Parmer) that was set off for 2 min (for membrane relaxation) every $10 \mathrm{~min}$. Membrane fouling was indicated by the trans-membrane pressure (TMP) increase, which was monitored with a manometer in mm Hg. The TMP increased gradually with time from an initial value of about $5 \mathrm{~mm} \mathrm{Hg}(0.67 \mathrm{kPa})$ to around $600 \mathrm{~mm} \mathrm{Hg}$ $(80 \mathrm{kPa})$ and then, the fouled membrane was washed thoroughly with running tap water to 
restore its permeability [20].

\subsection{MBR wastewater treatment experiment}

The wastewater treatment experiment was conducted in four phases in the laboratory at room temperature $\left(\sim 25{ }^{\circ} \mathrm{C}\right)$ (Table 2$)$. A short initial phase, termed as Phase 0 , was recorded for the original performance of the system in terms of organic and nutrient removals. Afterwards, the system was operated and optimized for more than 400 days for enhanced biological $\mathrm{P}$ removal together with $\mathrm{N}$ removal. The operation could be divided into three phases according to the $\mathrm{P}$ remvoal performance in relation to the different COD:N:P ratios and/or recirculation ratios (Table 2). From Phase I to Phase II, the P removal efficiency improved significantly. Phase III was operated for a long period to demonstrate the stable operation of the system and its nutrient removal performance. In addition, the organic content or the COD:TN:TP ratio decreased in the influent in Phase III compared to Phase II to increase the difficulty of biological nutrient removals. During this phase, the recirculation ratio was increased as an adjustment to maintain a high nutrient removal efficiency (Table 2). The treatment performance was evaluated in terms of the removal efficiencies of the total organic carbon (TOC), total $\mathrm{N}(\mathrm{TN})$, and total $\mathrm{P}(\mathrm{TP})$ as well as the $\mathrm{P}$ concentration profile in the liquid phase of the sludge suspensions through different tanks.

\subsection{Microscopic examination of PAOs}

The composition and spatial distribution of the microbial community of the sludge in relation to PAO-based $\mathrm{P}$ removal were examined under a fluorescent microscope after staining. DAPI (4',6'-diamidino-2-phenylindole) staining on all cells was performed following the method described by Kawaharasaki et al [21] using a filtered DAPI solution (10 $\mathrm{mg} / \mathrm{mL}$ in $25 \mathrm{mM}$ Tris-HCl buffered saline, $\mathrm{pH}$ 7.0). For a sludge sample taken from the 
aerobic tank, it was homogenized briefly using a vortex mixer (Maxi Mix II, Thermolyne) to break up large flocs. The dispersed biomass was then air-dried on a slide and stained with the DAPI solution. After 10 min of staining, the slide was washed using a phosphate buffer saline (PBS) solution and then air-dried at room temperature. The sample was examined under a fluorescent microscope (Eclipse, Nikon) with a $100 \mathrm{~W}$ high-pressure mercury lamp and a filter set MWU (Olympus Optical, excitation 330-385 nm). The DAPI-DNA fluorescence appeared to be blue white, while the fluorescence of either DAPI-poly-P or DAPI-lipid was bright yellow.

Fluorescence in situ hybridization (FISH) technique was also employed to characterize PAO in the sludge following the method described by Fu et al [22]. A sludge sample was first homogenized briefly using the vortex mixer and then placed in a hybridization well on a gelatin-coated microscopic slide plate. The $\mathrm{PAO}_{\text {mix }}$ probes (comprising the equal amount of probes $\mathrm{PAO}_{462}, \mathrm{PAO}_{651}$, and $\mathrm{PAO}_{846}$ (TechDragon, Hong Kong)) were used to target $\mathrm{PAO}$ species. Meanwhile, EUB338 was used to target all eubacteria in the sludge sample. The sample after staining was examined under an epifluorescent confocal laser scanning microscope (CLSM) (LSM Pascal, Zeiss, Thornwood). The combined use of DAPI staining and FISH also would display the abundance of PHB in the sludge [23].

\subsection{Analytical methods}

The influent and effluent of the MBR system were sampled twice a week for determination of the overall treatment performance in terms of the removals of the organic (TOC), total nitrogen $\left(\mathrm{NH}_{4}{ }^{+}-\mathrm{N}\right.$ and $\left.\mathrm{NO}_{3}{ }^{-}-\mathrm{N}\right)$, and total phosphorus $\left(\mathrm{PO}_{4}{ }^{3-}-\mathrm{P}\right)$. In addition, the sludge suspension was also sampled twice a week from each of the tanks and chambers for detail analysis. For the sludge samples, the suspensions were filtered through a $0.4-\mu \mathrm{m}$ polycarbonate membrane (25 mm, Osmonics) and the filtrates were analyzed. The TOC 
concentration was determined by a TOC analyzer (IL550 TOC-TN Analyzers, Lachat) using the combustion-infrared method. Ammonia nitrogen $\left(\mathrm{NH}_{4}{ }^{+}-\mathrm{N}\right)$ was analyzed using the electrochemical method with an ammonia electrode and a potentiometer (920A, ORION). Nitrate $\left(\mathrm{NO}_{3}{ }^{-}-\mathrm{N}\right)$ was analyzed by an UV/VIS spectrophotometer (Lambda 25, Perkin Elmer) according to the Standard Methods [24]. The liquid-phase P concentration in the sludge suspension was analyzed using a spectrophotometer (UV/VIS Lambda 12, Perkin Elmer) in accordance to the Standard Methods [24]. The dissolved oxygen (DO) concentration in each chamber was determined by a DO probe (97-08-99, Orion) with an electrometer (920A, Orion). Mixed liquor suspended solids (MLSS) for the sludge concentration and COD for the organic concentration were measured following the Standard Methods [24].

\section{Results and Discussion}

\subsection{Organic and nitrogen removal}

The MBR wastewater treatment system was operated for over 430 days under various conditions, including variations in food-to-microorganism (F/M) ratio, COD:TN:TP, and internal recirculation ratio, as summarized in Table 2. The MBR system performed consistently well in organic degradation and nitrification. In detail, the TOC removal efficiency was more than 94\% throughout the experiment (Fig. 2), even that a volumetric organic loading rate up to $720 \mathrm{mg}$ COD/L-d. The effluent contained a low organic concentration with a TOC below $5 \mathrm{mg} / \mathrm{L}$, which was not affected significantly by the variations in operation. The organic content in the supernatant of the anoxic tank was constantly below $25 \mathrm{mg}$ TOC/L. Thus, it is deduced that the major portion of the influent organic was degraded in the aerobic and anoxic tanks, with an average removal efficiency of around $85 \%$. The additional organic removal was attributable to the step of membrane filtration, due to its effective retention of organic solutes [25, 26]. Moreover, the membrane 
interception helped keep a relatively high biomass concentration in the MBR system, which made the system less sensitive to the changes in operation [27, 28]. Meanwhile, the effluent after membrane filtration was of high quality with a SS concentration of less than $1 \mathrm{mg} / \mathrm{L}$.

The average $\mathrm{NH}_{4}{ }^{+}-\mathrm{N}$ removal efficiency of the MBR system was about 92\%, indicating sufficient biological nitrification (Fig. 2). The aerobic zone followed by the anoxic zone formed a post-denitrification process for TN removal, and feeding the substrate into the anoxic tank was proven to effectively facilitate denitrification. An increase of the nitrogen loading rate or change of the COD/TN ratio did not significantly affect the $\mathrm{NH}_{4}{ }^{+}-\mathrm{N}$ removal efficiency. At a high volumetric nitrogen loading rate from 70 to $80 \mathrm{mg} \mathrm{N} / \mathrm{L}-\mathrm{d}$, the average TN removal efficiencies were 79.2 $\pm 4.3,78.8 \pm 3.4,83.7 \pm 3.0$, and $73.2 \pm 1.3 \%$ for Phases 0 , I, II, and III, respectively. However, the C:N ratio in the wastewater influent was important to the denitrification efficiency. As the C:N ratio decreased from 54:5 to 46.5:5 in Phase III, the effluent TN content increased considerably, due likely to the insufficient carbon source in the influent for denitrification. The recirculation ratio appeared to be another important factor to the TN removal result $[7,14,29]$. As $\mathrm{NO}_{3}{ }^{-} \mathrm{N}$ counted for around $90 \%$ of the TN residue in the MBR effluent, the TN removal efficiency by denitrification could be further improved if a higher recirculation ratio was adopted.

\subsection{Biologically-enhanced phosphorus removal}

The TP removal was no more than $40 \%$ during the start-up phase, or Phase 0 (Fig. 3), which also suggested that The $\mathrm{P}$ removal via assimilation was clearly below $40 \%$. The $\mathrm{P}$ concentration in the supernatant of sludge at the outlet of the anaerobic tank (i.e. the rough setter, DO $<0.05 \mathrm{mg} / \mathrm{L}$ ) was not significantly higher than that in the aerobic MBR suspension. This implies that the PAO community was not well developed in the system. For the EBPR process, $\mathrm{P}$ release by PAOs under anaerobic condition is crucial to the luxury P uptake in the 
subsequent aerobic stage $[7,30,31]$. Thus, conditions that favor PAO growth and anaerobic phosphorus release should be provided. As such, a longer anaerobic period (to 200 min) and a shorter SRT (to $\sim 10$ d) were adopted from day 31 (i.e. Phase I). The anaerobic P release was evidently improved gradually in the intermeidate sedimentation chamber, and the TP removal efficiency increased to nearly 50\% with an average effluent TP concentration of about 5.2 $\mathrm{mg} / \mathrm{L}$. In order to enhance PAO accumulation further, the COD/TP ratio was increased to more than 50 in Phase II. During this period, the TP removal efficiency increased gradually to over $75 \%$ and the effluent TP concentration decreased eventually to $2.2 \mathrm{mg} / \mathrm{L}$. The phenomena of $\mathrm{P}$ release in the anaerobic phase (intermediate sedimentation chamber) and $\mathrm{P}$ uptake in the aerobic phase (MBR tank) could be well observed. By the end of Phase II at a volumeric phosphorus loading rate of $15 \mathrm{mg}$ P/L-d, a fairly low effluent TP concentration of less than $2.0 \mathrm{mg} / \mathrm{L}$ was attained and the average P removal efficiency reached to $87.1 \%$ (Fig. $3)$.

In Phase III, the organic content (COD concentration) in the wastewater influent was reduced by more than 10\%, resulting in lower COD/TN and COD/TP ratios (Table 2). However, with a higher recirculation ratio applied $\left(4 \mathrm{Q}_{\mathrm{in}}+4 \mathrm{Q}_{\mathrm{in}}\right)$, the $\mathrm{TP}$ removal efficiency increased to over $88 \%$ with an average effluent TP concentration of around $0.8 \mathrm{mg} / \mathrm{L}$. Although decreased slightly, the TN removal rate was still around $80 \%$ (Fig. 2). The experimental results showed that the MBR system developed in this study is highly effective for sufficient organic degradation and simultaneous nutrient ( $\mathrm{N}$ and $\mathrm{P}$ ) removal. In this regard, this MBR system with a short treatment time $(\mathrm{HRT}<10 \mathrm{hr})$ and a high pollutant loading rate (720 mg COD/L-d, $77 \mathrm{mg}$ N/L-d and $15.4 \mathrm{mg}$ P/L-d) is comparable to or more effective than the MBR systems reported by others [11, 32] for simultaneous N and P removal. Moreover, the long-term experimental operaiton also evidenced the stable performance of the MBR-based treatment process. During the stable operation in Phase III, the specific nutrient 
removal rates could be estimated for the sludge in different reactors or tanks, and the results summarized in Table 3 include the specific nitrification, denitirfication, $\mathrm{P}$ release and $\mathrm{P}$ uptake rates.

Phosphrate release in the anaerobic zone is crucial to the PAO function for P-removal, and its performance is affected considerably by the form of the carbon source [7, 31]. In the anaerobic chamber (intermediate settler), acetate in the influent could be readily uptaken by PAO cells, leading to the activation of acetyl-CoA. Two molecules of acetyl-CoA could condense to form acetoacetyl-CoA, which would be transformed eventually to poly-b-hydroxybutyrate (PHB) [7, 33]. Subsequently, in the aerobic stage with a rather low organic concentration, PAOs could use PHB as the carbon and energy sources to grow and to assimilate $\mathrm{P}$ forming poly-P [31, 32]. The configuration and operation of the wastewater treatement process shown in Fig. 1 was apparently favorable to the growth of PAOs in the MBR system. In addition, a sufficient residence time of the sludge in the anaerobic chamber would ensure the conversion of readily degradable substrates to PHB, which is essential to the luxury P uptake in the aerobic stage [34, 35].

Phosphorus was then removed in the MBR via luxury P uptake and sludge discharge. The intermediate settler functioned not only for sludge-water separation, but also as an anaerobic chamber for P release. As half of the influent was fed into the anoxic tank, the organic carbon would induce P release in the intermediate sludge settler. Subsequently, luxury P uptake took place in the MBR to achieve P removal from the liquid phase. The P contents in the liquid phases of the sludge mixture in different tanks were analyzed when a high TP removal efficiency was maintained in Phase III (Fig. 4). With an influent P concentration of $8 \mathrm{mg} / \mathrm{L}$, the liquid-phase P concentrations in the aerobic tank, rough settler, and membrane chamber were $6.7,21.5$, and $1.5 \mathrm{mg} / \mathrm{L}$, respectively. In view of the sludge flow from the rough settler to the aerobic tank and membrane chamber, it becomes apparent that anaerobic P release and 
aerobic luxury P uptake occurred well in the system. The liquid-phase P contents showed the characteristic P distribution profile of the EBPR process. The membrane filtration also played a role in polishing the effluent for P removal, as indicated by a lower TP concentration in the effluent $(0.8 \mathrm{mg} / \mathrm{L})$ than that in the MBR sludge supernatant $(1.5 \mathrm{mg} / \mathrm{L})$. Comparing Phase III with Phase 0 for TP removal, it can be estimated that more than 56\% of phosphorus (112 mg P/d) was removed by the luxury P uptake of the sludge, whilst the other less than $40 \mathrm{mg}$ P/d was probably utilized for biomass growth.

\subsection{PAOs and their role in phosphorus removal}

PAO accumulation and function are crucial to the $\mathrm{P}$ removal capability of the MBR-based EBPR system. The PAO growth in sludge during the experiment was examined by microscopic observations. The aerobic sludge flocs in different test phases (0, I, II, and III) were stained by DAPI and the specific PAO probes $\left(\mathrm{PAO}_{\text {mix }}\right)[11,31,34]$. After DAPI staining, PAOs appeared as bright blue spots and polyhydroxybutyrate (PHB) appeared to be yellow dots. As for the FISH images of the sludge labeled with the PAO probe, PAOs appeared to be yellow clusters, as the probe would bind coccobacilli [35]. In the start-up phase, the activated sludge (Fig. $5 \mathrm{a}_{1}$ and $\mathrm{a}_{2}$ ) showed only a little PAO and PHB signals. With the development of the system for $\mathrm{P}$ removal, the PAO abundance in the sludge flocs increased gradually. For the sludge in Phase I during which the MBR exhibited a moderate P removal, the PAO and PHB contents increased considerably (Fig. $5 b_{1}$ and $b_{2}$ ).

In relation to the improvement of P removal in Phases II and III, the clusters of PAO probes binding with the distinct and uniform yellow cells can be well observed (Fig. $5 \mathrm{c}_{2}$ and $d_{2}$ ). Moreover, large PHB granules were displayed by the bright yellow spots (Fig. $5 c_{1}$ and $d_{1}$ ), which confirmed further the PAO activities. The apparent PAO content and PHB density correlated well with the P removal performance of the EBPR system. For example, compared 
to the early sludge samples, the sludge flocs in Phase III had more compact and larger PAO clusters. It is believed that the massive PAO clustering signified the great P release and uptake activities of the sludge under the anaerobic and aerobic conditions, respectively [2, 34].

\subsection{Sludge concentration profile}

The membrane fouling in MBR is caused mainly by sludge depostion on the membrane surface $[6,20,26]$. Previous studies have shown that the membrane fouling rate in MBR is affected to a certain extent by the bulk sludge concentration [20, 36, 37]. It would be beneficial to the membrane fouling reduction if the sludge concentration in the membrane chamber could be maintained at a low level (e.g. $<6$ g MLSS/L) [28]. The present MBR system employed a rough settler for sludge-water separtion before the membrane chamber. This would therefore help lower the sludge concentration in the membrane chamber while increase the MLSS contents in other tanks to favor biological treatment activities. During the operation of the MBR system for over 400 days, the average sludge concentration in the membrane chamber (3 g MLSS/L) was found to be even lower than that in the aerobic tank (3.6 g/L) (Fig. 6). If the rough settler was not employed, the membrane chamber would have the highest sludge concentration in comparion to other tanks, which would likely lead to more rapid membrane fouling [6, 36, 37]. During the stable operation in Phase III, the overflow from the rough settler into the MBR had a sludge concentration (MLSS) of around $1.9 \mathrm{mg} / \mathrm{L}$. This was considerably lower than the sludge concentration $(\sim 3.0 \mathrm{~g} / \mathrm{L})$ in the upstream bioreactors. Because of the membrane separation, the effluent was free of solids and sludge in the MBR tank was concentrated to about $2.4 \mathrm{~g} / \mathrm{L}$. The sludge mixture was recirculated at a rate of $4 \mathrm{Q}_{\text {in }}\left(\mathrm{Q}_{\text {in }}=16.6 \mathrm{~L} / \mathrm{d}\right)$. Meanwhile, for a stable operation and effective P removal, the sludge mixture was discharged from the MBR at a rate of about $0.7 \mathrm{~L} / \mathrm{d}$. 
4. Conclusions

- An innovative MBR system was developed for effective organic degradation and nutrient removal in wastewater treatment. The system integrated membrane filtration with the post-denitrification activated sludge process, and the wastewater influent was split into the aerobic tank and the anoxic tank. A rough settler was used not only for sludge-water separation before membrane filtration but also as an anaerobic chamber for $\mathrm{P}$ release.

- The MBR-based system performed remarkably well for simultaneous organic, $\mathrm{N}$ and $\mathrm{P}$ removals. With a short treatment time of less than 10 hrs, the system could achieve stable TOC, TN, and TP removal efficiencies of around 94\%, $85 \%$, and $87 \%$, with effluent concentrations of less than 5,6 , and $1 \mathrm{mg} / \mathrm{L}$, respectively.

- The proliferation and activity of PAOs in the MBR system were indicated by the significant $\mathrm{P}$ release in the anaerobic chamber and the luxury $\mathrm{P}$ uptake in the aerobic membrane chamber. PAOs and their P accumulating function were evidenced by the large PAO clusters and PHB granules under the fluorescent microscope after DAPI and PAOM probe staining.

\section{Acknowledgement}

This research was supported by grant HKU714811E from the Research Grants Council (RGC) of the Government of Hong Kong SAR, grant 51129803 from the Natural Science Foundation of China, and grant KQCX20120802095942112 of the Shenzhen Peacock Technique Funding Project. The technical assistance of Mr. Keith C.H. Wong is highly appreciated.

\section{References}


[1] Mino T, van Loosdrecht MCM, Heijnen JJ. Microbiology and biochemistry of the enhanced biological phosphate removal process. Water Res 1998; 32: 3193-207.

[2] Oehmen A, Zeng RJ, Yuan ZG, Keller J. Anaerobic metabolism of propionate by polyphosphate-accumulating organisms in enhanced biological phosphorus removal systems. Biotechnol Bioeng 2005; 91: 43-53.

[3] Metcalf \& Eddy. Wastewater Engineering: Treatment and Reuse, $4^{\text {th }}$ ed. McGraw-Hill, Boston, Massachusetts, USA; 2003.

[4] Coats ER, Mockos A, Loge FJ. Post-anoxic denitrification driven by PHA and glycogen within enhanced biological phosphorus removal. Biores Technol 2011; 102: 1019-27.

[5] Judd S. The MBR Book: Principles and Applications of Membrane Bioreactors in Water and Wastewater Treatment. Amsterdam, The Netherlands: Elsevier; 2006.

[6] Meng FG, Chae SR, Drew A, Kraume M, Shin HS, Yang FL. Recent advances in membrane bioreactors (MBRs): Membrane fouling and membrane material. Water Res 2009; 43: 1489-512.

[7] Oehmen A, Lemos PC, Carvalho G, Yuan Z, Keller J, Blackall LL, Reis MAM. Advances in enhanced biological phosphorus removal: From micro to macro scale. Water Res 2007; 41: 2271-300.

[8] Monclús H, Sipma J, Ferrero G, Comas J, Rodriguez-Rod I. Optimization of biological nutrient removal in a pilot plant UCT-MBR treating municipal wastewater during start-up. Desalination 2010; 250: 592-7.

[9] Adam C, Gnirss R, Lesjean B, Buisson H, Kraume M. Enhanced biological phosphorus removal in membrane bioreactors. Water Sci Technol 2002 ; 46: 281-6.

[10] Zhang HM, Xiao JN, Cheng YJ, Liu LF, Zhang XW, Yang FL. Comparison between a sequencing batch membrane bioreactor and a conventional membrane bioreactor. Process Biochem 2006; 41: 87-95. 
[11] Yang S, Yang F, Fu Z, Wang T, Lei R. Simultaneous nitrogen and phosphorus removal by a novel sequencing batch moving bed membrane bioreactor for wastewater treatment. J Hazard Mater 2010; 175: 551-7.

[12] Wang Y, Huang X, Yuan Q. Nitrogen and carbon removals from food processing wastewater by an anoxic/aerobic membrane bioreactor. Process Biochem 2005; 40: 1733-39.

[13] Shen J, He R, Han W, Sun X, Li J, Wang L. Biological denitrification of high-nitrate wastewater in a modified anoxic/oxic-membrane bioreactor (A/O-MBR). J Hazard Mater 2009; 172: 595-600.

[14] Vocks M, Adama C, Lesjean B, Gnirssc R, Kraume M. Enhanced post-denitrification without addition of an external carbon source in membrane bioreactors. Water Res 2005; 39: 3360-68.

[15] Hu Y, Wang XC, Zhang Y, Li Y, Chen H, Jin P. Characteristics of an A2O-MBR system for reclaimed water production under constant flux at low TMP. J Membr Sci 2013; 431: $156-162$.

[16] Gòmez-Silván C, Arévalo J, Pérez J, González-López J, Rodelas B. Linking hydrolytic activities to variables influencing a submerged membrane bioreactor (MBR) treating urban wastewater under real operating conditions. Water Res 2013; 47: 66-78.

[17] Shen YX, Xiao K, Liang P, Sun JY, Sai SJ, Huang X. Characterization of soluble microbial products in 10 large-scale membrane bioreactors for municipal wastewater treatment in China. J Membr Sci 2012; 415-416: 336-345.

[18] Ivanovic I, Leiknes T. Impact of aeration rates on particle colloidal fraction in the biofilm membrane bioreactor (BF-MBR). Desalination 2008; 231: 182-90.

[19] AEESP. Environmental Engineering Process Laboratory Manual. Champaign, IL, USA: Association of Environmental Engineering and Science Professors; 2001. 
[20] Chu HP, Li XY. Membrane fouling in a membrane bioreactor (SMBR): Sludge cake formation and fouling characteristics. Biotechnol Bioeng 2005; 90: 323-31.

[21] Kawaharasaki M, Tanaka H, Kanagawa T, Nakamura K. In situ identification of polyphosphate-accumulating bacteria in activated sludge by dual staining with rRNA-targeted oligonucleotide probes and 4',6-diamidino-2-phenylindol (DAPI) at a polyphosphate-probing concentration. Water Res. 1999; 33: 257-65.

[22] Fu Z, Yang F, An Y, Xue Y. Simultaneous nitrification and denitrification coupled with phosphorus removal in a modified anoxic/oxic-membrane bioreactor (A/O-MBR). Biochem Eng J 2009; 43: 191-6.

[23] Tsai CS, Liu WT. Phylogenetic and physiological diversity of tetrad-forming organisms in deteriorated biological phosphorus removal systems. Water Sci Technol 2002; 46(1-2): 179-84.

[24] APHA-AWWA-WEF. Standard Methods for the Examination of Water and Wastewater, 20th ed. Washington, DC, USA: American Public Health Association/American Water Works Association/Water Environment Federation; 1998.

[25] Liang S, Liu C, Song L. Soluble microbial products in membrane bioreactor operation: behaviors, characteristics, and fouling potential. Water Res 2007; 41: 95-101.

[26] Wang XM, Li XY. Accumulation of biopolymer clusters in a submerged membrane bioreactor and its effect on membrane fouling. Water Res 2008; 42: 855-62.

[27] Chae SR, Shin HS. Characteristics of simultaneous organic and nutrient removal in a pilot-scale vertical submerged membrane bioreactor (VSMBR) treating municipal wastewater at various temperatures. Process Biochem 2007; 42: 193-8.

[28] Monti A, Hall ER, Dawson RN, Husain H, Kelly H. Comparative study of biological nutrient removal (BNR) processes with sedimentation and membrane-based separation. Biotechnol Bioeng 2006; 96: 740-52. 
[29] Rosenberger S, Evenblij H, Poele ST, Wintgens T, Laabs C. The importance of liquid phase analyses to understand fouling in membrane assisted activated sludge processes-six case studies of different European research groups. J Membr Sci 2005; 263: 113-26.

[30] Wachtmeister A, Kuba T, van Loosdrecht MCM, Heijnen JJ. A sludge characterization assay for aerobic and denitrifying phosphorus removing sludge. Wat Res 1997; 31: $471-478$.

[31] Liu Y, Zhang T, Fang HHP. Microbial community analysis and performance of a phosphate-removing activated sludge. Biores Technol 2005; 96: 1205-14.

[32] Shin JH, Lee SM, Jung J.Y. Enhanced COD and nitrogen removals for the treatment of swine wastewater by combining submerged membrane bioreactor (MBR) and anaerobic upflow bed filter (AUBF) reactor. Process Biochem 2005; 40: 3769-76.

[33] Ersu CB, Ong SK, Arslankaya E, Lee YW. Impact of solids residence time on biological nutrient removal performance of membrane bioreactor. Water Res 2010; 44: 3192-202.

[34] Seviour RJ, Mino T, Onuki M. The microbiology of biological phosphorus removal in activated sludge systems. FEMS Microbiol Rev 2003; 27: 99-127.

[35] Lee N, Janssen JL, Aspegren H, Henze M, Nielsen PH, Wagner M. Population dynamics in wastewater treatment plants with enhanced biological phosphorus removal operated with and without nitrogen removal. Water Sci Technol 2002; 46: 163-70.

[36] Li XY, Wang XM. Modelling of membrane fouling in a submerged membrane bioreactor. J Membr Sci 2006; 278: 151-61.

[37] Meng F, Zhang H, Yang F, Zhang S, Li Y, Zhang X. Identification of activated sludge properties affecting membrane fouling in submerged membrane bioreactors. Sep Purif Technol 2006; 51: 95-103. 
Table 1. Summary of a few large-scale MBR processes for biological nutrient removals in wastewater treatment

\begin{tabular}{|c|c|c|c|c|c|c|c|c|c|c|c|}
\hline \multirow[b]{2}{*}{ Process } & \multirow[b]{2}{*}{$\begin{array}{l}\text { Capacity } \\
\left(\mathrm{m}^{3} / \mathrm{d}\right)\end{array}$} & \multirow[b]{2}{*}{$\begin{array}{c}\text { Membrane } \\
\text { material }\end{array}$} & \multicolumn{3}{|c|}{ Operating conditions } & \multicolumn{3}{|c|}{ Effluent quality } & \multirow[b]{2}{*}{$\begin{array}{l}\text { Membrane } \\
\text { cleaning } \\
\text { cycle }\end{array}$} & \multirow[b]{2}{*}{$\begin{array}{c}\text { Features and } \\
\text { limitations }\end{array}$} & \multirow[b]{2}{*}{ Ref. } \\
\hline & & & $\begin{array}{l}\mathrm{HRT} \\
\text { (h) }\end{array}$ & $\begin{array}{l}\text { SRT } \\
\text { (d) }\end{array}$ & $\begin{array}{c}\text { MLSS } \\
\text { in MBR } \\
(\mathrm{g} / \mathrm{L})\end{array}$ & $\begin{array}{l}\text { COD } \\
(\mathrm{mg} / \mathrm{L})\end{array}$ & $\begin{array}{c}\mathrm{TN} \\
(\mathrm{mg} / \mathrm{L})\end{array}$ & $\begin{array}{c}\mathrm{TP} \\
(\mathrm{mg} / \mathrm{L})\end{array}$ & & & \\
\hline $\begin{array}{c}\text { Post-denitrification } \\
+ \text { MBR }\end{array}$ & 200 & PVDF & 38 & 20 & 4 & $20.1 \pm 14.8$ & $24.6 \pm 3.6$ & n.a. & weekly & $\begin{array}{l}\text { Stable operation; but a } \\
\text { long HRT. }\end{array}$ & [16] \\
\hline $\mathrm{A}_{1}-\mathrm{A}_{2}-\mathrm{O}-\mathrm{MBR}$ & 60,000 & $\begin{array}{l}0.04 \mu \mathrm{m}, \\
\text { PVDF }\end{array}$ & 17.3 & 20 & $7.00-8.50$ & $15 \sim 20$ & $15 \sim 25$ & $0.30 \sim 0.50$ & n.a & $\begin{array}{l}\text { Stable pollutant removal; } \\
\text { but a long HRT and low } \\
\text { filtration flux. }\end{array}$ & \\
\hline$A_{1}-A_{2}-A_{2}-O-M B R$ & 50,000 & $\begin{array}{l}0.1 \mu \mathrm{m} \\
\text { PVDF }\end{array}$ & $12 \sim 13$ & $25 \sim 32$ & $5.65 \sim 10.44$ & $8 \sim 53$ & $4.20 \sim 22.70$ & $0.03 \sim 1.45$ & n.a. & $\begin{array}{l}\text { Treatment of both } \\
\text { municipal and industrial } \\
\text { wastewater; but less } \\
\text { stable pollutant removal. }\end{array}$ & [17] \\
\hline $\mathrm{A}_{1}-\mathrm{A}_{2}-\mathrm{O}-\mathrm{MBR}$ & 20,000 & $\begin{array}{l}0.04 \mu \mathrm{m} \\
\text { PVDF }\end{array}$ & $10 \sim 14$ & 14 & $3.24 \sim 12.00$ & $8 \sim 91$ & $3.42 \sim 18.66$ & $0.05 \sim 0.89$ & n.a. & $\begin{array}{l}\text { High resistance to the } \\
\text { seasonal shocking; but } \\
\text { low filtration flux. }\end{array}$ & \\
\hline
\end{tabular}

Note: $\mathrm{A}_{1}$ - anaerobic; $\mathrm{A}_{2}$ - anoxic; $\mathrm{O}$ - oxic (aerobic); n.a.- not available. 
Table 2. The experimental condition in different phases for the MBR nutrient removal study.

\begin{tabular}{cccccccccc}
\hline \hline Phase $\begin{array}{c}\text { Duration } \\
(\mathrm{d})\end{array}$ & $\begin{array}{c}\text { SRT } \\
(\mathrm{d})\end{array}$ & $\begin{array}{c}\text { HRT } \\
(\mathrm{hr})\end{array}$ & $\begin{array}{c}\text { COD } \\
(\mathrm{mg} / \mathrm{L})\end{array}$ & $\begin{array}{c}\text { TOC } \\
(\mathrm{mg} / \mathrm{L})\end{array}$ & $\begin{array}{c}\text { F/M } \\
(\mathrm{g} \text { COD/g } \\
\text { MLSS-d })\end{array}$ & $\begin{array}{c}\text { TN } \\
(\mathrm{mg} / \mathrm{L})\end{array}$ & COD:TN:TP & $\begin{array}{c}\text { Recirculation } \\
\text { rate }\end{array}$ \\
\hline 0 & 30 & $>12$ & 11.6 & 320 & 120 & $\sim 0.32$ & 40 & $32: 4: 1$ & $3 \mathrm{Q}_{\text {in }}+3 \mathrm{Q}_{\text {in }}$ \\
\hline I & 83 & $\sim 10$ & 11.6 & 320 & 120 & $\sim 0.22$ & 40 & $32: 4: 1$ & $3 \mathrm{Q}_{\text {in }}+3 \mathrm{Q}_{\text {in }}$ \\
\hline II & 153 & $\sim 10$ & 9.3 & 432 & 160 & $\sim 0.26$ & 40 & $54: 5: 1$ & $3 \mathrm{Q}_{\text {in }}+3 \mathrm{Q}_{\text {in }}$ \\
\hline III & 165 & $\sim 10$ & 9.3 & 372 & 140 & $\sim 0.28$ & 40 & $46.5: 5: 1$ & $4 \mathrm{Q}_{\text {in }}+4 \mathrm{Q}_{\text {in }}$ \\
\hline \hline
\end{tabular}


Table 3. Specific biological $\mathrm{N}$ and $\mathrm{P}$ removal rates estimated for the sludge in different reactors during the stable operation in Phase III.

\begin{tabular}{ccccc}
\hline $\begin{array}{c}\text { Specific nutrient } \\
\text { removal rate }\end{array}$ & Aerobic tank & Anoxic tank + sludge settler & MBR \\
\hline Volume (L) & 2.0 & 1.4 & 1.5 & 1.6 \\
HRT (hr) & 2.9 & 2.0 & 2.1 & 2.3 \\
MLSS (g/L) & 3.0 & 3.0 & 3.0 & 2.4 \\
\hline Nitrification & 45 & & & \\
$($ mg N/g MLSS-d) & & & & \\
\hline Denitrification & & & \\
$($ mg N/g MLSS-d) & & & \\
\hline P release & & & \\
$(m g$ P/g MLSS-d) & & & \\
\hline P uptake & & & \\
\hline
\end{tabular}




\section{Figure captions}

Fig. 1. Schematic diagram of the new MBR system for organic degradation and simultaneous $\mathrm{N}$ and $\mathrm{P}$ removal.

Fig. 2. Organic and total nitrogen removal performance of the MBR system (OM: organic matter measured by mg TOC/L).

Fig. 3. Total phosphorus removal in different phases (Phase 0, I, II, and III) of the MBR experiment.

Fig. 4. Change of the phosphate concentration in the liquid phase of the sludge in different tanks of the MBR system during Phase III operation.

Fig. 5. Microscopic images of the PAOs in the MBR sludge after (1) DAPI staining (bright blue spots - live bacteria stained by DAPI; yellow dots - PHB stained by DAPI) and (2) FISH-CLSM observation (green spots - bacteria stained by EUB338; yellow area - PAO stained by $\mathrm{PAO}_{\text {mix }}$ ): (a) seed sludge in Phase 0 , (b) sludge flocs in Phase I, (c) sludge flocs in Phase II, and (d) sludge flocs in Phase III.

Fig. 6. The MLSS concentrations of the sludge in the aerobic tank and MBR chamber. 


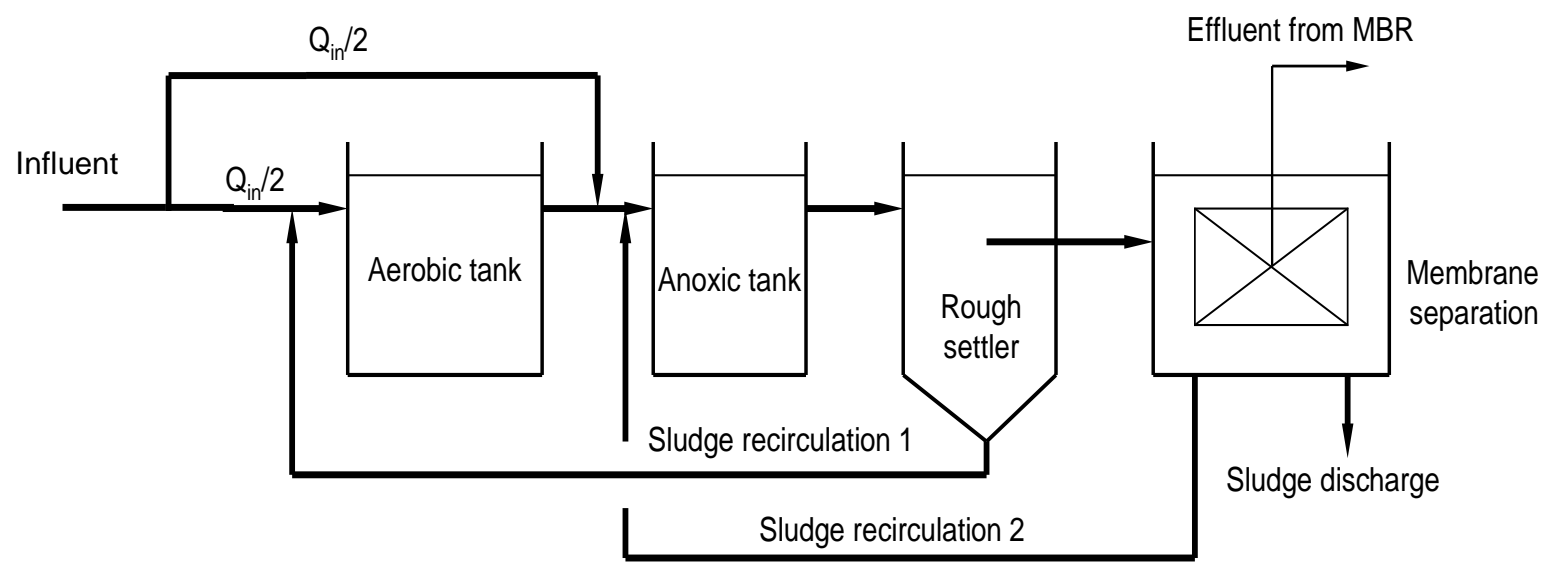

Fig. 1. Schematic diagram of the new MBR system for organic degradation and simultaneous $\mathrm{N}$ and $\mathrm{P}$ removal. 


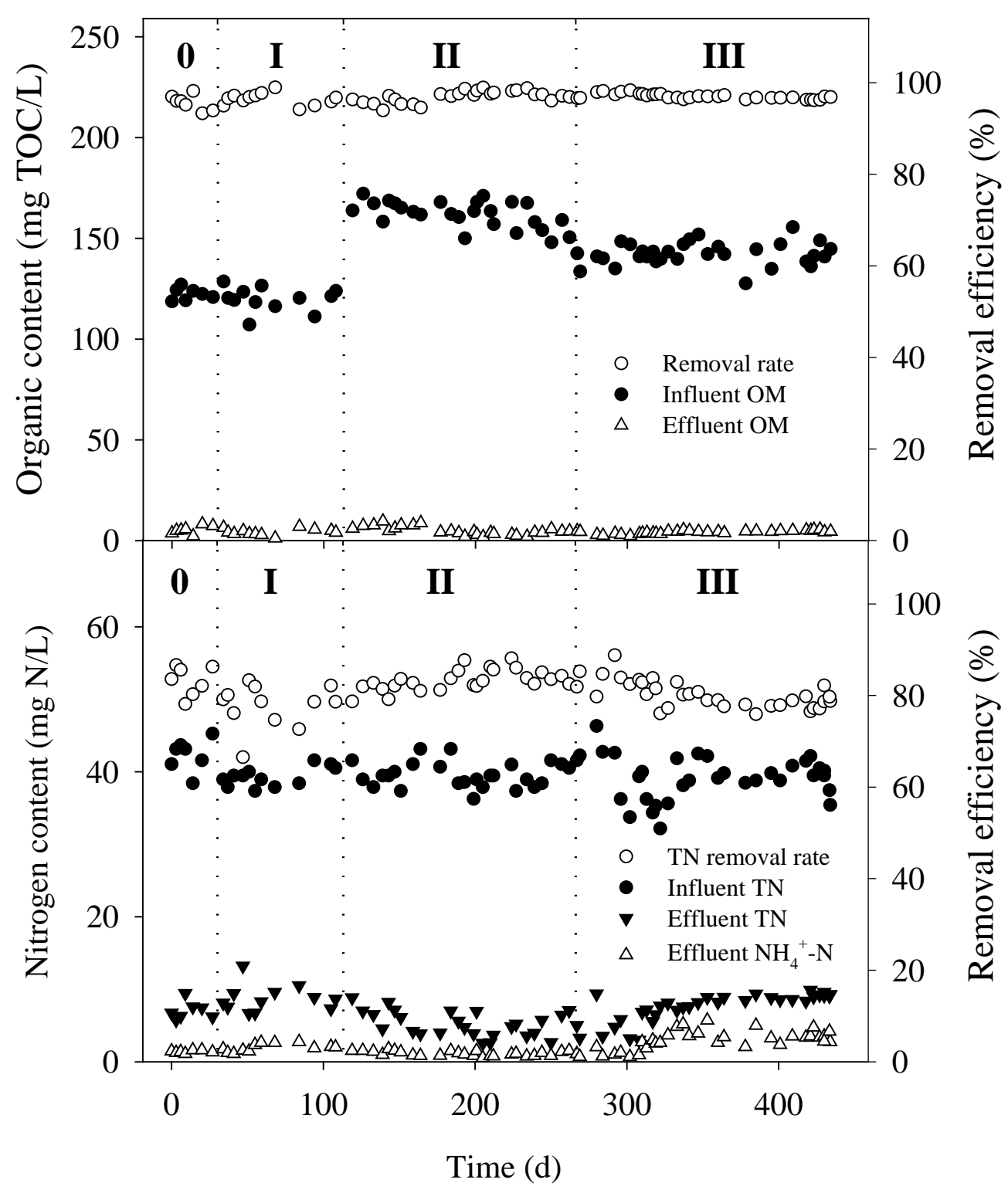

Fig. 2. Organic and total nitrogen removal performance of the MBR system (OM: organic matter measured by mg TOC/L). 


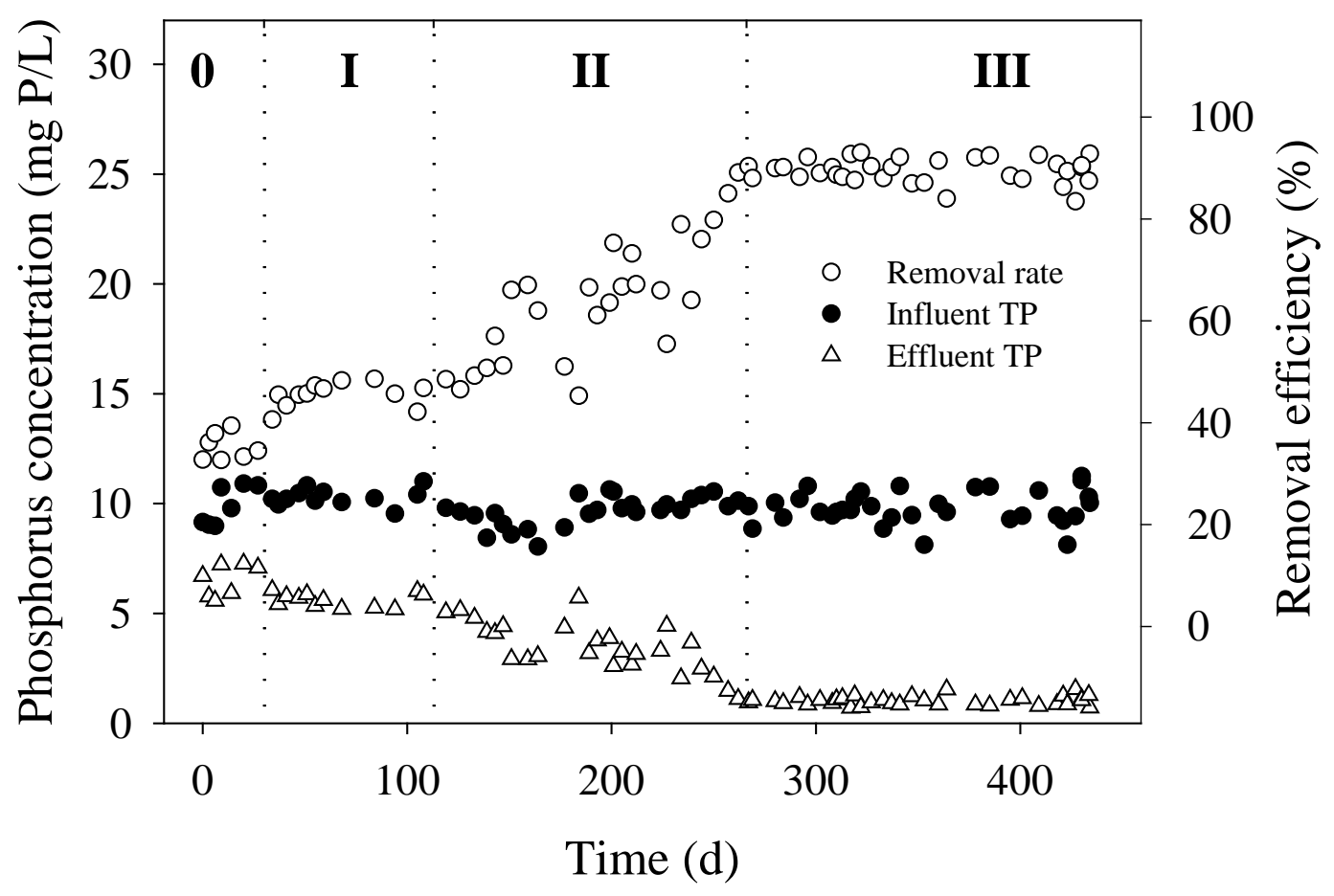

Fig. 3. Total phosphorus removal in different phases (Phase 0, I, II, and III) of the MBR experiment. 


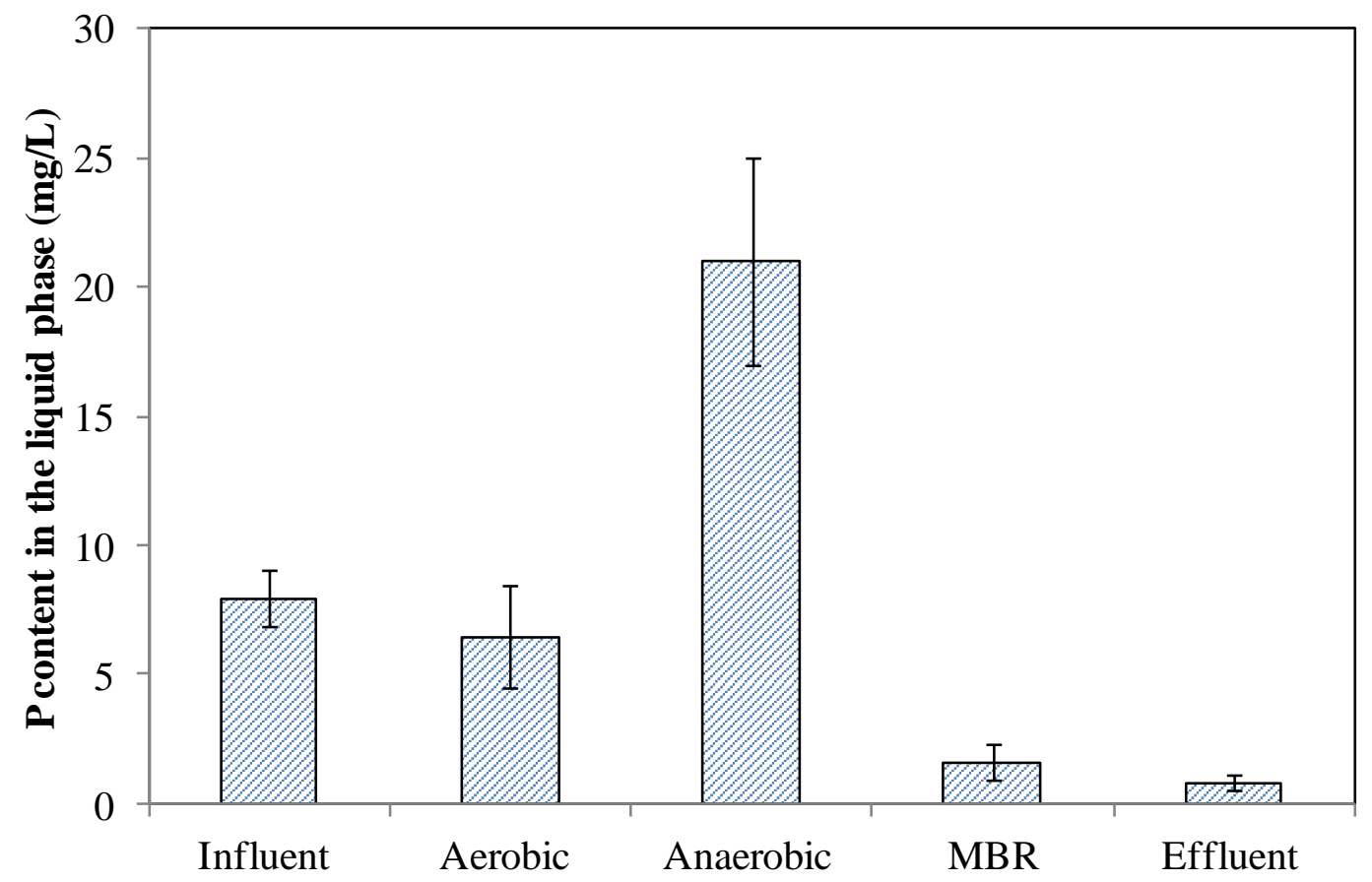

Fig. 4. Change of the phosphate concentration in the liquid phase of the sludge in different tanks of the MBR system during Phase III operation. 


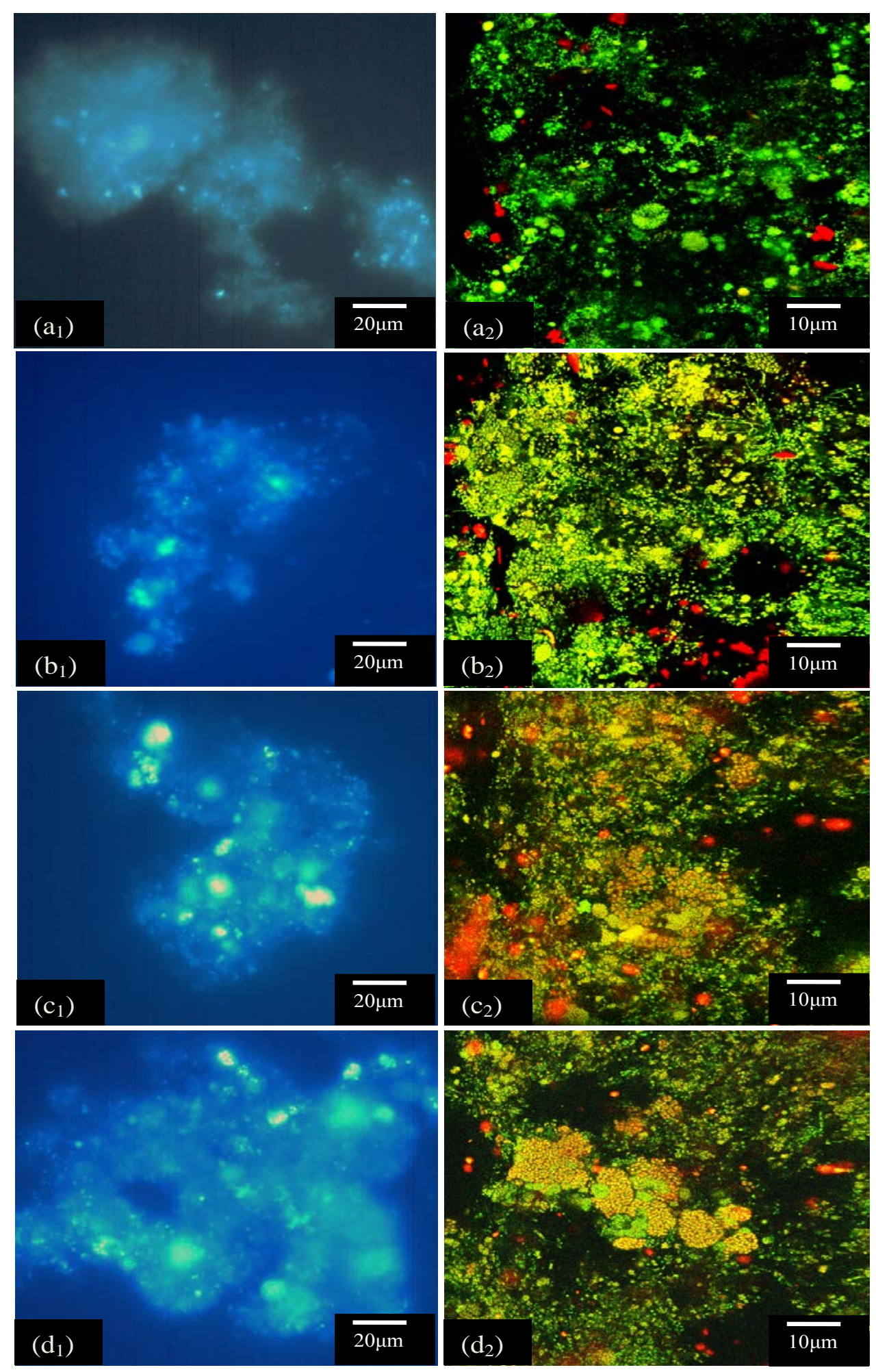

Fig. 5. Microscopic images of the PAOs in the MBR sludge after (1) DAPI staining (bright blue spots - live bacteria stained by DAPI; yellow dots - PHB stained by DAPI) and (2) FISH-CLSM observation (green spots - bacteria stained by EUB338; yellow area - PAO stained by $\mathrm{PAO}_{\mathrm{mix}}$ ): (a) seed sludge in Phase 0, (b) sludge flocs in Phase I, (c) sludge flocs in Phase II, and (d) sludge flocs in Phase III. 


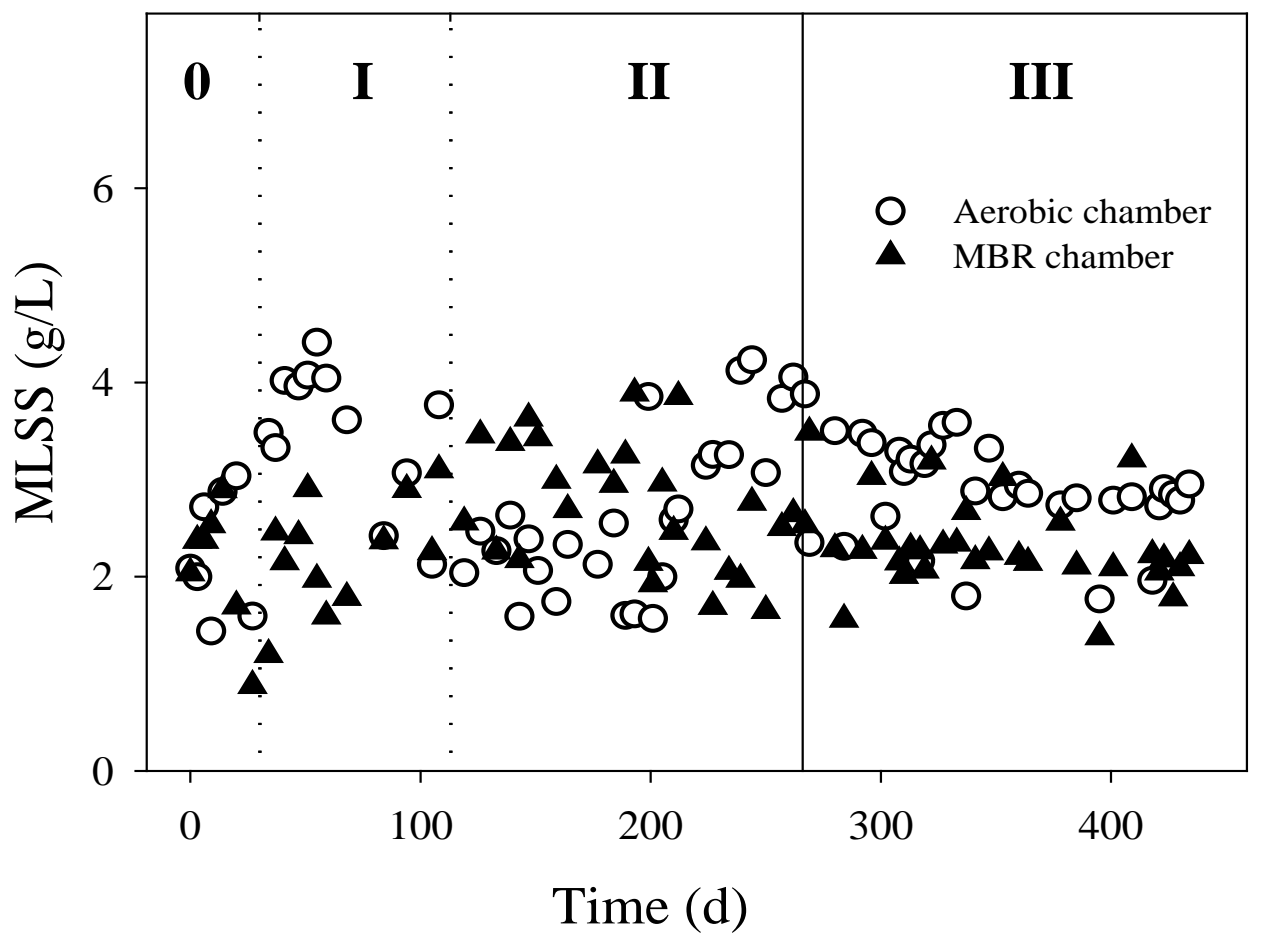

Fig. 6. The MLSS concentrations of the sludge in the aerobic tank and MBR chamber. 